\title{
Numerical Analysis of the Hot-spot Temperature of a Power Transformer with Alternative Dielectric Liquids
}

\author{
A. Santisteban, F. Delgado, A. Ortiz, I. Fernández, C.J. Renedo and F. Ortiz \\ Dept. Electrical and Energy Engineering (ETSII) \\ University of Cantabria \\ Santander, Spain
}

\begin{abstract}
The assessment of two vegetal oils as coolant in Low Voltage Winding of a power transformer with zigzag cooling have been analyzed. These dielectric fluids cooling performance has been compared with a typical mineral oil. To make the study, a 2Daxisymmetrical model of a power transformer has been developed to perform a numerical analysis using a Finite Element Method based software, COMSOL Multiphysics ${ }^{\circledR}$. Some values are obtained in order to establish the comparison, such as hot-spot temperature or hot-spot factor. Moreover, the influence of the increase of the number of passes of the cooling circuit on the hot-spot temperature has been evaluated for all liquids and compared with the initial design. Results obtained in this work show that the hot-spot temperature is lower for the vegetal oils in the initial design. Furthermore, an increase in the number of passes affect more positively to the mineral oil since similar values of the hot-spot temperature for all liquids are obtained. Values of the hot-spot factor indicates that higher number of passes leads to lower efficient cooling circuits owing to the increase of the pressure drop although the hot-spot temperature decreases.
\end{abstract}

Index Terms - Power transformer, thermal modelling, conjugate heat transfer, alternative dielectric liquids, hot-spot temperature.

\section{INTRODUCTION}

POWER transformers are one of the main devices in transmission and power supply networks. Although their efficiency is over $99 \%$, the amount of power losses they produce leads to a harmful heating of the device. The highest temperature obtained, also known as hot-spot temperature, is a value that affects directly to the degradation of transformer insulation system and thus the machine lifetime. Due to this, it becomes necessary to add a cooling system inside the transformer. For small distribution transformer it is enough with ambient air but for large power transformers more efficient cooling is needed to ensure their performance. In this case, the most extended coolant is mineral oil. Its dielectric properties added to its low viscosity has made this fluid the main coolant in power transformers for over a hundred years. The problems that mineral oil presents are its low flash and ignition point and its low biodegradability. Those facts have encouraged the development of new alternative dielectric liquids that overcome the problems previously announced. This kind of liquids are divided in four groups: high molecular weight hydrocarbons, silicone-based oils, vegetal oils and synthetic esters. All of them have an ignition point over $300^{\circ} \mathrm{C}$, but only the last two types are biodegradable [1]. To determine the cooling capacity of these fluids in a power transformer, a numerical analysis can be carried out. There are two main techniques for this analysis, first is the Thermal-Hydraulic Network Model (THNM) and second is the Computational Fluid Dynamics (CFD).

In the literature, some papers can be found where these techniques are employed to numerically predict hot spot temperature and temperature distributions in oil immersed transformers. Some authors used CFD techniques to develop their studies like Mufuta et al. [2] who used a commercial CFD software to characterize the oil flow through an array of discs with different spaces between discs and different inlet conditions or El Wakil et al [3] employed a 2D axisymmetric model of a power transformer with six different geometries and six different inlet velocities in order to study the oil flow. Torriano et al [4] performed simulations of a low-voltage winding (LVW) of a power transformer with zigzag cooling in order to determine the accuracy of different 2D axisymmetric models based on coupling CFD and heat transfer. In 2011, Gastelurrutia et al [5] carried out a study where the developed a 3D and a 2D model of an ONAN (Oil Natural-Air Natural) distribution transformer by using CFD techniques. The simplified 2D model has a good capacity to represent the thermal behavior of the whole transformer. In 2012, Tsili et al [6] established a methodology to develop a 3D model to predict hot-spot temperature by coupling fluid flow and heat transfer via Finite Element Method (FEM). They applied the 
developed method to predict hot-spot temperatures and temperature profiles for two distribution transformers. In this year, Skillen et al [7] carried out a CFD simulation of a 2D non-isothermal flow axisymmetric model in order to characterize the oil flow in transformer winding with zigzag cooling. Also, Torriano et al [8] performed a 2D axisymmetric and a 3D simulation of a transformer winding with zigzag cooling to determine the effects of elements of the transformer, such as sticks and intersticks, in the temperature distribution. In 2014, Yatsevsky [9] carried out a 2D axisymmetric simulation of a Conjugate Heat Transfer (CHT) model of a transformer, including the core, the tank and the radiator, in order to predict hot-spots in an oil immersed transformer with natural convection. The developed model has shown a good adequacy verified by experiments.

Other authors used the THNM techniques to perform their analyses. For example Rahimpour et al [10] in 2007, used THNM techniques to determine which parameters affect the hot-spot temperature magnitude in a zigzag cooled transformer winding. In 2008, Zhang et al [11] created a THNM for an oil immersed transformer winding with zigzag cooling and established empirical correlations to determine the local heat transfer coefficients, developing a thermal model with good agreement with experimental results.

Some authors have studied parameters affecting the temperature profiles in mineral oil transformers via CFD techniques. In 2006, Zhang and Li [12] performed a 2D thermal analysis to determine the influence of some geometrical parameters such as number of disk per pass, width and height of horizontal and vertical channels and oil inlet conditions on the value and location of hot-spots in a mineral oil immersed transformer winding. In 2008, Hosseini et al [13] performed a simulation of an oil directed high voltage winding of a power transformer immersed in mineral oil and the influence of the design parameters in the hot-spot temperature value and location. Later in 2009, Taghikhani et al. [14] employed a $2 \mathrm{D}$ heat transfer model of a power transformer to predict hot-spot value and location including the influence of Directed Oil Flow (DOF) and Non-Directed Oil Flow (NDOF) configurations. In 2010, Sorgic and Radakovic [15] carried out a 2D simulation of a mineral oil immersed transformer in order to compare the cooling system with Oil Forced and Oil Directed configuration.

On the other hand, the substitution of mineral oil by new biodegradable dielectrics liquids with higher ignition points has been the target of different studies for some time. However, few experimental and theoretical works can be found in literature related with esters cooling capacity. For instance, in 2010 Girgis et al. [16] compared the temperatures measured with fiber-optic sensors using alternatively a natural ester and a mineral oil as coolant in a 50 MVA commercial transformer. In 2015 Park et al [17] employed a 2D CFD model in order to obtain temperature and velocity profiles of some alternative liquids used in a distribution transformer of 2.3 MVA and a power transformer of 16.5 MVA. In the same year, Lecuna et al [18] carried out a
3D CFD simulation of an ONAN distribution transformer comparing a natural ester, a synthetic ester, a high kinematic viscosity silicone oil and a low kinematic viscosity silicone oil with a mineral oil. These works conclude that alternative liquids produce higher temperatures in the transformer windings designed for mineral oil.

Notwithstanding the higher temperature in the windings, there are multiple experiences in which transformers designed for mineral oil were filled with biodegradable esters [16, 19]. In addition, the retro filling of transformers with esters is outlined in the standards that deal with these fluids [20, 21].

Other works present the advantages of using natural esters in the transformer insulation system. In 2016, Mehta et al. presents two reviews [22, 23] in which many properties of both types of liquids are compared. As a result of this comparison, it is concluded that natural esters are acceptable for both new transformers and for retro filling existing units. In the same year, Fernandez et al published a work [24] in which laboratory experiments and CFD simulations are combined to study the influence of vegetable oils in the lifespan of the winding insulation paper. It was concluded that, even though the paper suffers worse thermal conditions when it is immersed in vegetable oils, the physical properties of these oils extend the lifespan of this paper. That is, in the long term, both effects tend to the balance and the degradation is similar to the one obtained in windings cooled by mineral oil.

To contribute to the characterization of these new liquids, a new work is presented here. The goal of this paper is to perform a 2D CFD simulation of two vegetal oils in a LVW of a power transformer with zigzag cooling, establishing a comparison of thermal capacity with a mineral oil. In addition, an analysis of the influence of number of passes on the hotspot temperature for both types of liquid is carried out. The increase of pressure drop will be pointed out for each fluid. This last perspective has not been considered in the literature published up to now.

This work is organized as follows: Section 2 presents the methodology applied, including the geometry description and numerical model. Section 3 presents the model validation. Section 4 presents the results obtained and its discussion and finally, Section 5 presents the conclusions of the study.

\section{METHODOLOGY}

This section describes the proposed methodology to solve the CHT problem in a 2D axisymmetric model solved via finite elements.

\subsection{GEOMETRY DESCRIPTION}

The geometry of the study represents a LVW of a 66 MVA power transformer. Due to computational requirements, some simplifications are assumed to obtain a 2D-axisymmetric model of the winding which is fully described in [8].

The whole winding, which is shown in Figure 1 consists of 78 discs divided in four passes separated by oil washers with 19 discs each and an inlet section with two discs and an additional washer. Each pass has an inner and an outer axial 
duct of 8.9 and $6.4 \mathrm{~mm}$ width respectively. The oil enters in one pass from one axial duct and exits from the other axial duct, alternating this sequence in successive passes. Discs are separated by horizontal ducts of $4.1 \mathrm{~mm}$ height each. Therefore each pass has 20 horizontal ducts which allow the oil flow from one axial duct to the other. Each disc of the winding is composed by 18 copper conductors individually wrapped with a layer of insulation paper of $0.4 \mathrm{~mm}$ thickness, composing a winding disc of $50.8 \mathrm{~mm}$ width and $15 \mathrm{~mm}$ height.

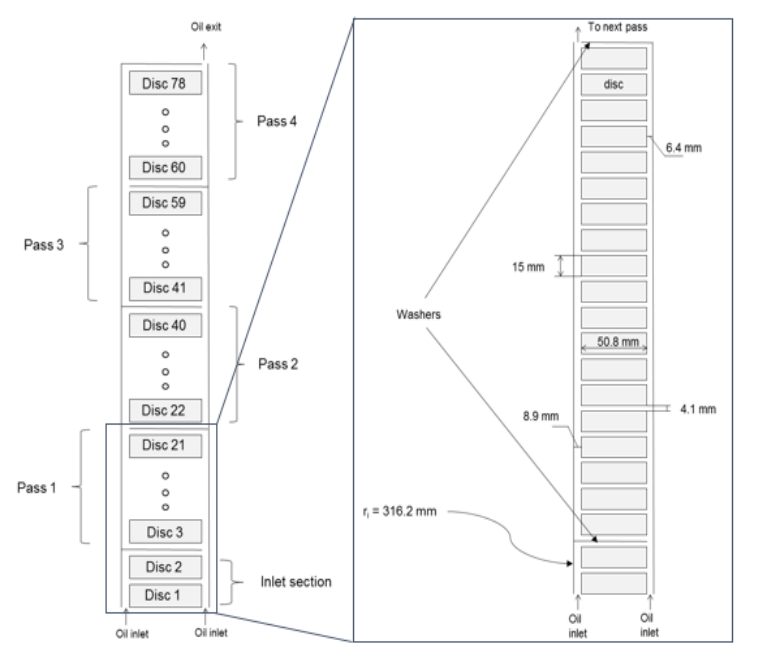

Figure 1. LVW geometry.

\subsection{NUMERICAL MODEL}

This subsection describes the numerical model that represents the problem to solve.

\subsubsection{GOVERNING EQUATIONS}

The present study combines the physics principles of fluid dynamics and heat transfer. For fluid domain, the NavierStokes equations (mass conservation, momentum conservation and energy conservation) need to be solved to reach a stationary solution (equations (1)-(3)).

$$
\begin{gathered}
\nabla \cdot(\rho w)=0 \\
\nabla \cdot(\rho w \times w)=-\nabla p+\mu\left(\nabla^{2} w\right)+g\left(\rho-\beta_{h \alpha}\right) \\
\nabla \cdot\left(\rho \rho_{w} u T\right)=\nabla \cdot\left(\alpha \Delta T^{2}\right)+Q
\end{gathered}
$$

The right-hand terms of equation (2) represents the pressure force, the viscous force and the buoyancy force respectively. Buoyancy forces are caused by oil density variations with temperature.

The equation that govern the solid domain is the heat conduction equation in a solid as shown in equation (4)

$$
\theta=\nabla \cdot(\operatorname{la} \pi \tau)+q_{a}
$$

Where the term $\mathrm{q}_{\mathrm{s}}$ represents the whole losses in the winding (Joule and eddy losses).

\subsubsection{BOUNDARY CONDITIONS}

The boundary conditions applied in this study are the conditions reported in [4] for the CHT model. For the fluid inlet, a mass flow rate of $0.78 \mathrm{~kg} / \mathrm{s}$ at a temperature of $46.7^{\circ} \mathrm{C}$ is defined. At the fluid outlet, a pressure condition of $0 \mathrm{~Pa}$ is set. At the fluid-solid interphase, a no slip condition is considered. In the whole fluid domain, buoyancy forces are taken into account.

For the solid domain, a uniform heat source of $676.9 \mathrm{~W} /$ disc is specified, representing the sum of the Joule and eddy losses. For the lowest disc, a heat transfer coefficient of $100 \mathrm{~W} / \mathrm{m} 2 \cdot \mathrm{K}$ is set on the bottom surface of the disc [8].

The exterior walls of the domain are made of thick cardboard of low conductivity which is considered negligible in the model, as adiabatic walls. Figure 2 represents the boundary conditions of the model.

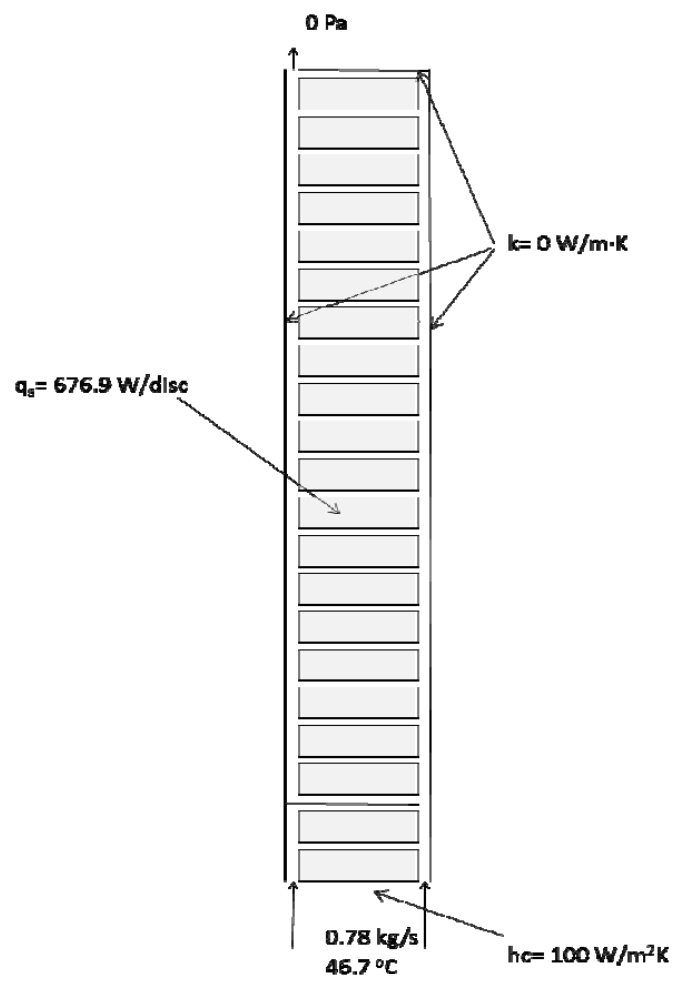

Figure 2. Boundary conditions of the model

\subsubsection{MATERIAL PROPERTIES}

In the present study two vegetal oils and a mineral oil are considered as a coolant of the transformer. Figure 3 represents the properties of the two vegetal oils and the mineral oil (properties of mineral oil obtained from [3]) used for the simulations. In this Figure, it can be appreciated that mineral oil has lower density, thermal conductivity and kinematic viscosity than both vegetal oils, whereas the specific heat has similar values for all fluids. From a hydraulic point of view, mineral oil has better properties than vegetal oils. On the other hand, thermal properties of the vegetal oils are better than the mineral oil ones. Moreover, all properties except for specific heat decrease with temperature. Dynamic viscosity, hereinafter referred to as viscosity, is the product of kinematic viscosity and density and takes lower values for the mineral oil with respect to the vegetal oils. 

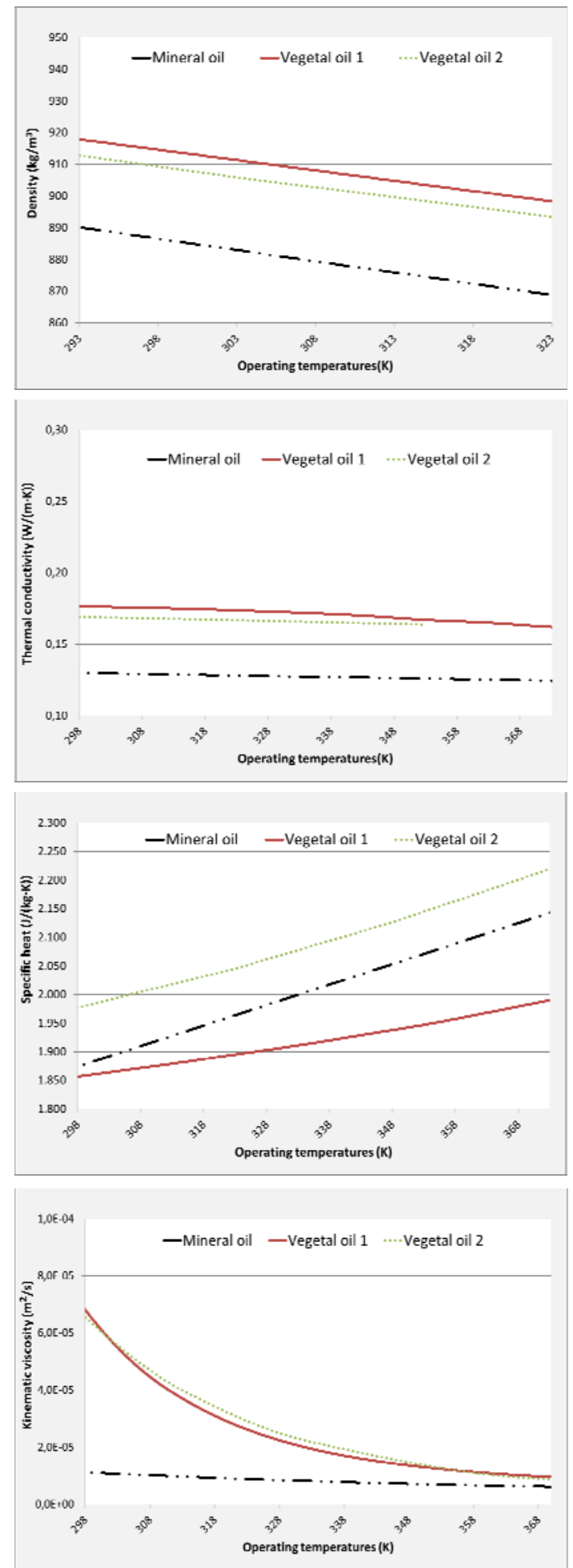

Figure 3. Physical properties of the dielectric liquids.

The winding discs are made of copper and insulation paper and their properties, which are considered temperature independent, are included in Table 1 [4]:

Table 1. Physical properties of solid materials

\begin{tabular}{ccc}
$\rho$ & $\mathrm{k}$ & $\mathrm{C}_{\mathrm{p}}$ \\
{$\left[\mathrm{kg} / \mathrm{m}^{3}\right]$} & {$[\mathrm{W} /(\mathrm{m} \mathrm{K})]$} & {$[\mathrm{J} /(\mathrm{kg} \mathrm{K})]$} \\
\hline
\end{tabular}

\begin{tabular}{lccc}
\cline { 1 - 1 } Copper & 8,700 & 400 & 385 \\
Paper & 930 & 0.19 & 1,340 \\
\hline
\end{tabular}

\subsubsection{COMPUTATIONAL DOMAIN AND MESH}

The computational domain considers the cooling channels and the winding discs to reach a stationary solution via FEM. In order to perform the simulations, a commercial FEM software called COMSOL Multiphysics ${ }^{\circledR}$ v5.2 was employed. This program uses a CHT module to solve the problem previously described.

With the purpose of reducing computational requirements, a sequential study was performed in this work by simulating one pass, with the aforementioned boundary conditions, and using the values obtained at the outlet sections as inlet values of the following pass. Each pass is compound of 2,500,000 rectangular cells for the whole geometry with a maximum size of $0.1 \mathrm{~mm}$. This provides a detailed solution of the fluid flow and heat transfer in the transformer.

Simulations were carried out in a workstation Dell Precision T5500, with two processors at $2.66 \mathrm{GHz}$ and $48 \mathrm{~GB}$ of RAM taking between 8 and 10 hours to reach a solution for each case.

\subsection{HOT SPOT FACTOR}

In order to determine the efficiency of the cooling circuit, the hot-spot factor $(\mathrm{H})$ is studied. This parameter is described in the standards [25] and consists of the product of two parameters: $\mathrm{Q}$ and $\mathrm{S}$. $\mathrm{Q}$ depends on the ratio between the specific loss in the region of the leakage flux concentration (top winding) and the average specific loss of the winding, and $S$ is related to the efficiency of the cooling circuits inside the winding. Parameter $\mathrm{Q}$ has the same value in all cases studied since uniform heat losses in the winding and the same load factor have been considered in all cases. For this reason $\mathrm{H}$ indicates the efficiency of the cooling circuit, where higher values of $\mathrm{H}$ means lower efficiency. Hot-spot factor is calculated in this case from hot-spot temperature following equation (5)

$$
H=Q \cdot g=\frac{\tau_{h}-\tau_{s}}{\tau_{w}-0 . \mathrm{E} \cdot\left(\tau_{\mathrm{s}}+\tau_{\mathrm{h}}\right)}
$$

Where $T_{h}$ is the hot spot temperature, $T_{0}$ is the top oil temperature, $T_{b}$ is the bottom oil temperature and $T w$ is the average winding temperature, all of them being obtained from simulations.

\section{MODEL VALIDATION}

With the aim of validating the model developed and estimate its accuracy, a simulation of one single pass of the transformer has been carried out and the results obtained of average disc temperature, $\mathrm{T}_{\mathrm{h}}$, hot-spot location (HSL), oil velocity distribution, $\mathrm{T}_{\mathrm{w}}$ and $\mathrm{T}_{0}$, have been compared with the ones presented in [4] with the complete CHT model. In turn, it is necessary to clarify that the numerical model of this reference has been successfully validated by 
comparison with the fiber-optic measurements of an entire low-voltage winding of an operating transformer.

Figure 4 shows the average temperature of discs obtained from the simulation and from [4]. It can be appreciated that similar values are obtained since the maximum error is $0.7 \%$ on the mean temperature and the mean discrepancy is $0.44 \%$. The value of $\mathrm{T}_{\mathrm{h}}$ obtained in [4] is $95.4{ }^{\circ} \mathrm{C}$ whereas the value obtained from the simulation is $95.6{ }^{\circ} \mathrm{C}$, which means an error of $0.21 \%$. The HSL is the same for both cases, appearing in the 16th disc. The mass flow fraction through each horizontal channel is represented in Figure 5, the obtained curve fits well with the presented in the reference [4].

Comparing the $\mathrm{T}_{\mathrm{w}}$, a value of $76.8^{\circ} \mathrm{C}$ is obtained from simulations whereas a value of $76.6^{\circ} \mathrm{C}$ is set as a reference from [4]. The value of $\mathrm{T}_{\mathrm{o}}$ computed is $54.0^{\circ} \mathrm{C}$ whereas the value obtained from [4] is $55.1{ }^{\circ} \mathrm{C}$. Results obtained indicate that the developed model is accurate enough.

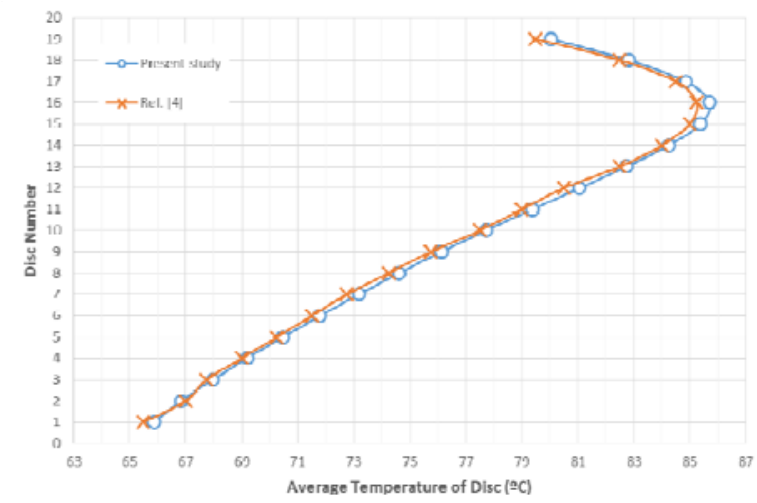

Figure 4. Average disc temperature in comparison with Ref. [4]

Figure 4 represents the mass flow fraction through horizontal channels in both studies, the highest discrepancies can be seen in the first channel.

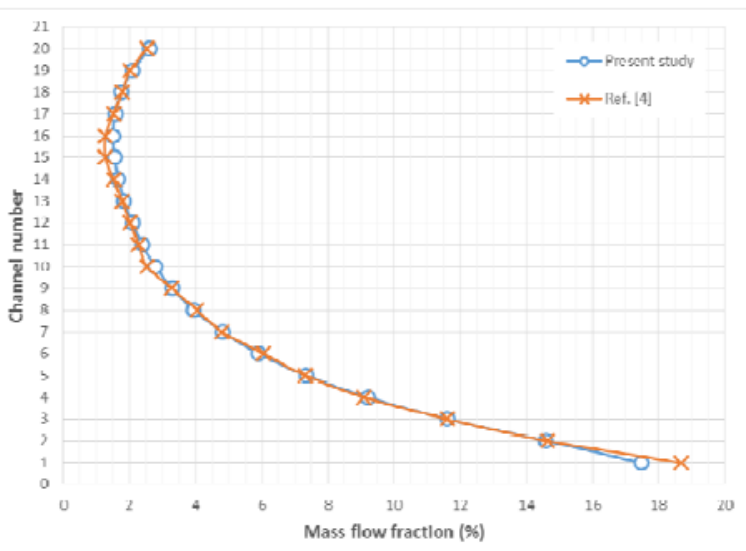

Figure 5. Mass flow fraction through horizontal channels.

\section{RESULTS AND DISCUSSION}

In the following section, results obtained from the aforementioned model are presented, focusing on the temperature distributions and the hot-spot temperature. In all cases, the inlet section results are not shown although they are considered for simulations.

\subsection{INITIAL CASE}

First case to be analyzed is the one described in the previous sections, a four pass cooling circuit with all dielectric liquids studied in this work. Figure 6 shows the temperature obtained in the windings and the HSL for all liquids studied. It can be appreciated that higher temperatures are obtained in the mineral oil. Figure 7 shows the average temperature of each disc of the winding for the three liquids studied, where the shape of the described curve for both vegetal oils is close to each other and different from mineral oil as a result of their higher density and viscosity.

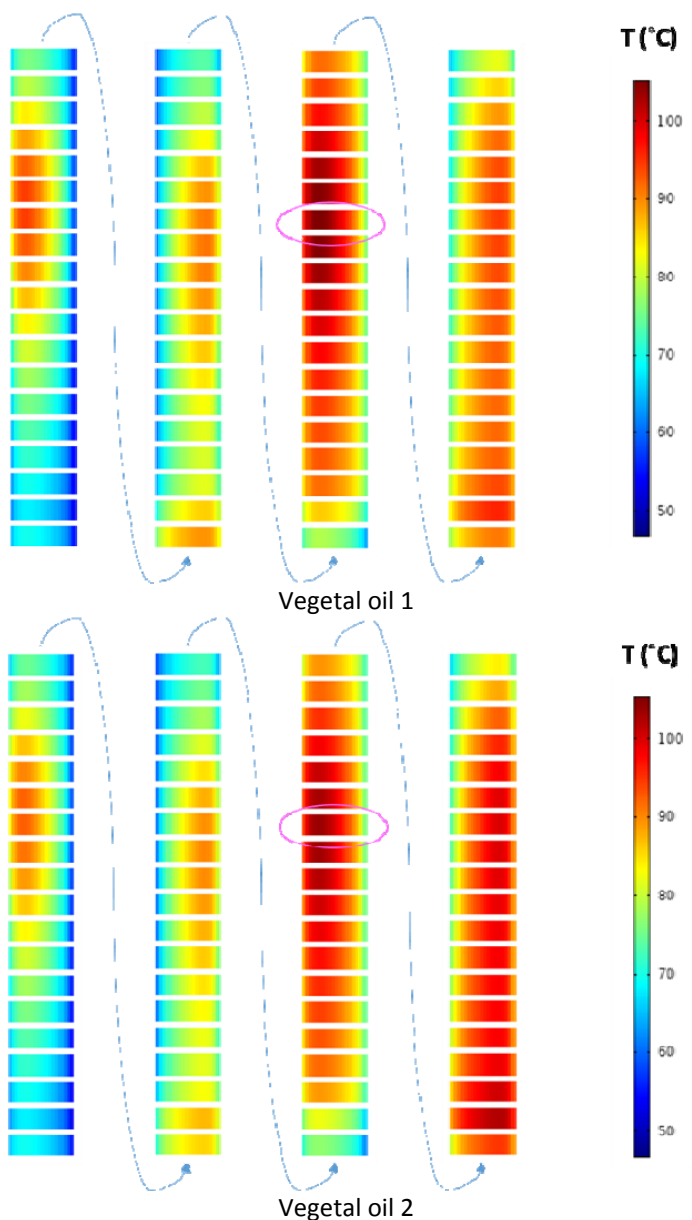



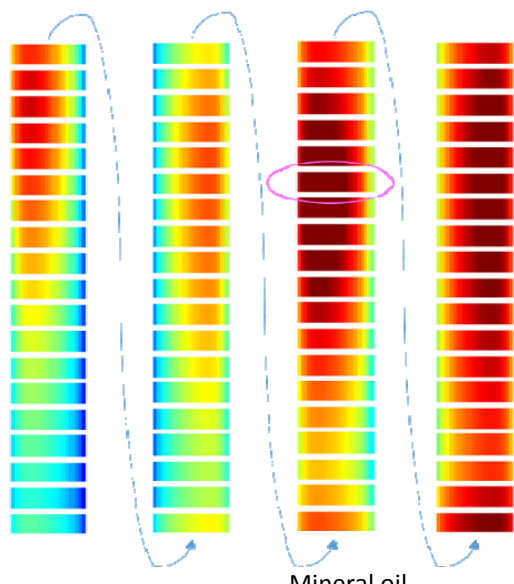

$T\left(f^{\circ} \mathrm{C}\right)$

Mineral oil

Figure 6 Temperature and HSL.

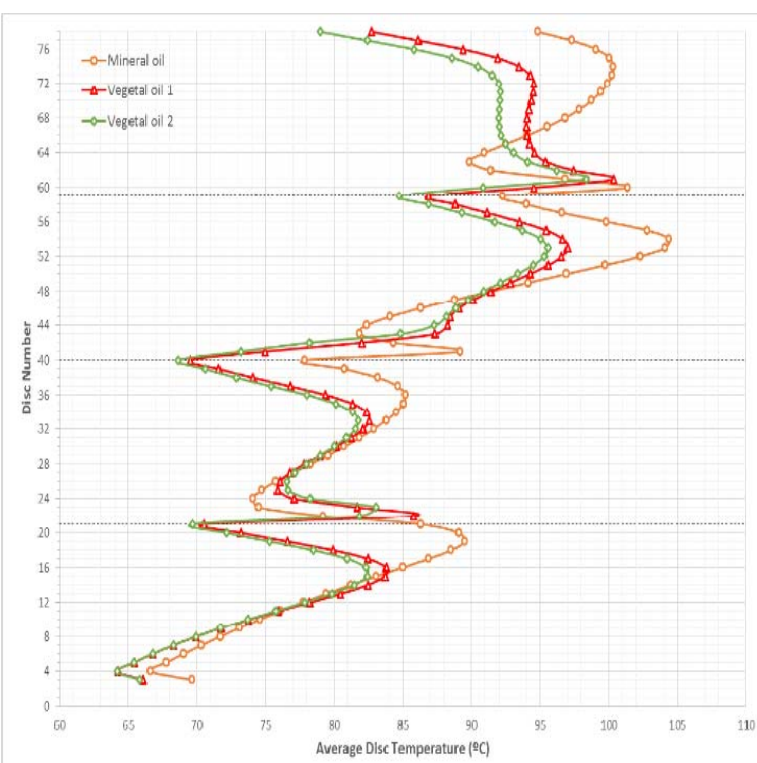

Figure 7. Average temperature of discs

In these Figures can be seen that the initial discs for the second and fourth passes are at higher temperatures than the following discs in the same pass. This effect is caused by the formation of hot streaks in the oil. These hot streaks pass from one axial duct to the other through the first horizontal channels of the mentioned pass increasing the oil temperature at the surface of these discs. Figure 8 represents the oil temperature obtained for each liquids, where hot streaks in the oil are remarked. For the mineral oil it is observed that in the third pass appears a cold streak between the 3rd and 5th channels, which is formed at the end of the second pass. A second cold streak appears in the oil at the end of the fourth pass. Both cold streaks are represented in Figure 8.
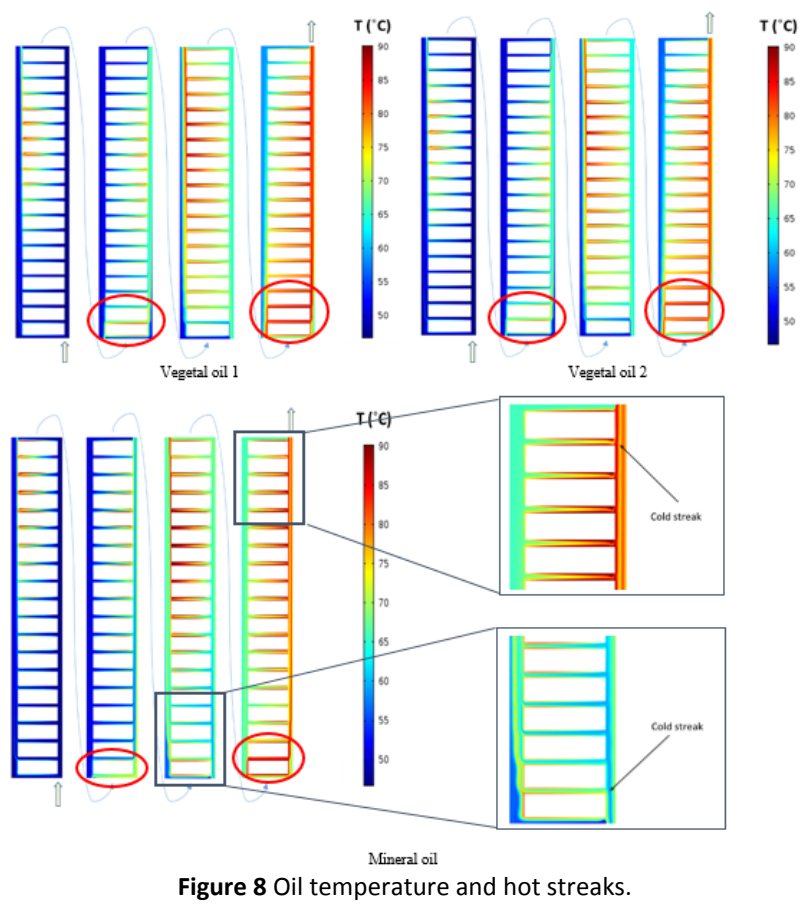

Table 2 contains the values of $\mathrm{T}_{\mathrm{o}}, \mathrm{T}_{\mathrm{w}}$ and $\mathrm{T}_{\mathrm{h}}$ and also the HSL obtained in each case studied. These values will be used for calculation of $\mathrm{H}$ as described in [25]. From this Table can be observed that the hot-spot temperature for both vegetal oils between is an $8-10 \%$ lower than for the mineral oil.

\begin{tabular}{|c|c|c|c|c|}
\hline & To $\left({ }^{\circ} \mathrm{C}\right)$ & $\mathrm{Tw}\left({ }^{\circ} \mathrm{C}\right)$ & Th $\left({ }^{\circ} \mathrm{C}\right)$ & HSL \\
\hline Mineral oil & 79.0 & 86.7 & 114.7 & Disc 54 \\
\hline $\begin{array}{c}\text { Vegetal oil } \\
1\end{array}$ & 78.5 & 83.8 & 105.3 & Disc 53 \\
\hline $\begin{array}{c}\text { Vegetal oil } \\
2\end{array}$ & 75.4 & 82.6 & 103.5 & Disc 53 \\
\hline
\end{tabular}

Figure 9 shows the mass flow fraction flowing through horizontal channels in each pass. It can be appreciated that for both vegetal oils the velocity distribution is very similar, existing a difference between them and mineral oil. The main fact that produces this difference on the velocity profile as well as the difference on the temperature patterns is the lower viscosity and density of the mineral oil, which improves the flow. The higher viscous forces obtained in both vegetal oils makes buoyancy forces less influential. This fact produces a different velocity profile and consequently a different temperature distribution as shown in Figures 6 and 7. 


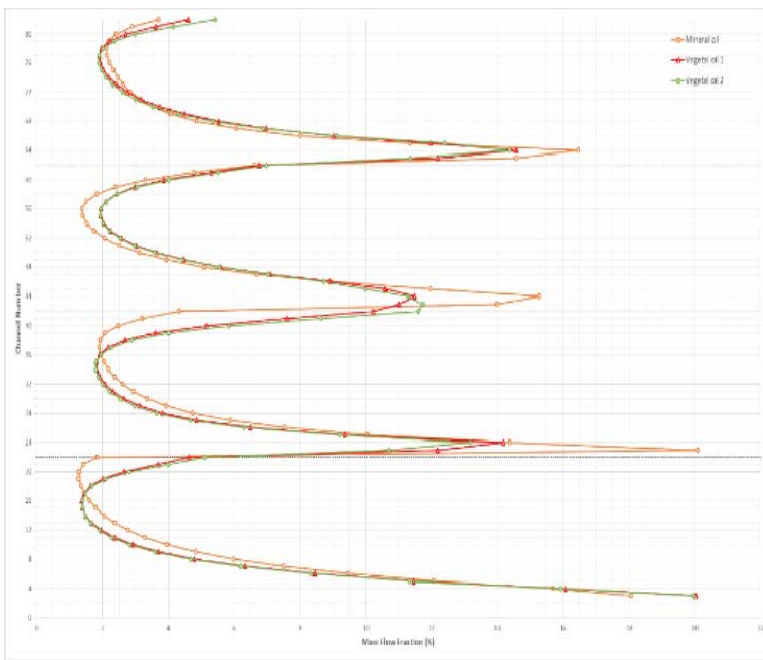

Figure 9. Mass flow fraction through horizontal channels.

The effects of worse hydraulic properties of the vegetal oils, with respect to the mineral oil, are overcame by its better thermal properties, considering the same mass flow inlet than the mineral oil. This means that both vegetal oils produce a lower hot-spot temperature than mineral oil.

\subsection{NUMBER OF PASS INFLUENCE}

An analysis of the influence of number of passes of the cooling circuit on the hot-spot temperature for both types of liquid has been carried out. The increase of the number of passes is achieved by the addition of new washers in different positions without altering the dimensions of the elements that form the cooling circuit (horizontal channels height and vertical ducts width). The same inlet conditions, oil mass flow rate and temperature, and the same boundary conditions as the base case are considered in all cases. As a result of the increase of the number of passes, a longer path has to be covered by the liquid. Table 3 indicates the distribution of the discs in the cases considered.

Table 3. Discs distribution for all case

\begin{tabular}{|cc|}
\hline 5 pass case & 15 discs per pass +3 bottom discs \\
6 pass case & 13 discs per pass \\
7 pass case & 11 discs per pass +1 bottom disc \\
8 pass case & 9 discs per pass +6 bottom discs \\
11 pass case & 7 discs per pass +1 bottom discs \\
\hline
\end{tabular}

\subsubsection{FIVE PASS CASE}

Figure 10 shows the winding temperature, the HSL and the hot streaks obtained with all liquids considered in this work for a five pass cooling circuit in the power transformer. In this case, the hot-spot is located in the $5^{\text {th }}$ pass, being at $3 / 4$ of the pass height for the mineral oil and $1 / 4$ of the total pass height for both vegetal oils. In this Figure can be observed differences in the temperature distribution of the windings between mineral and vegetal oils. Also can be appreciated that for the mineral oil, a hot streak appears in the lower part of the $3^{\text {rd }}$ and $5^{\text {th }}$ passes and a cold streak at the end of the $5^{\text {th }}$ one as well. For both vegetal oils these hot streaks appears in the lower part of the $3^{\text {rd }}, 4^{\text {th }}$ and $5^{\text {th }}$ passes whereas no cold streaks are observed. The effects of the hot streaks are less influential than in the base case since they are distributed through more horizontal channels.

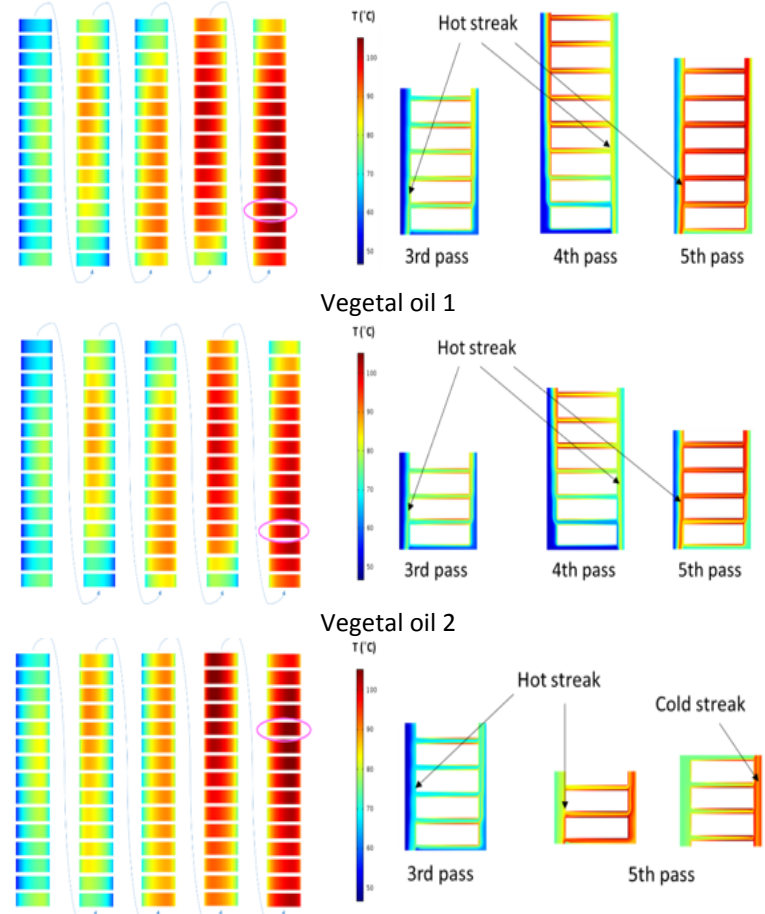

Mineral oil

Figure 10. Winding temperature and hot and cold streaks for five pass configuration.

Figure 11 represents the average temperature of each winding disc obtained with all liquids considered. It can be seen that the shape of the curve formed by both vegetal oils is very similar to each other, and different of the mineral oil. In this case, a different profile is obtained with respect to the previous case, and also lower temperatures can be observed.

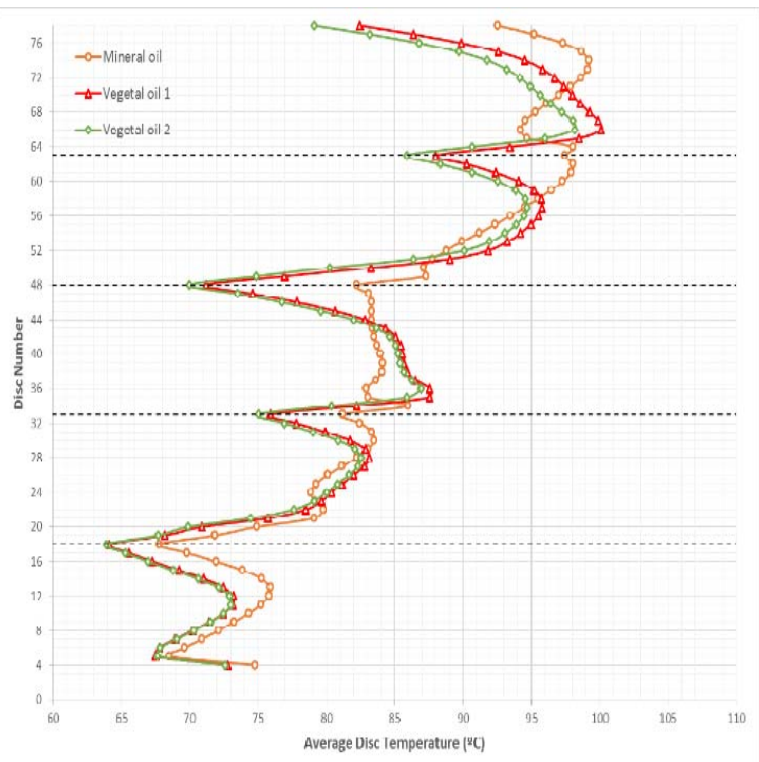

Figure 11. Average temperature of discs with 5 pass geometry. 
Table 4 contains the values of $T_{0}, T_{w}$ and $T_{h}$ and also the HSL with all liquids studied in this case. Temperatures are reduced with respect to the base case, obtaining a decrease of $7 \%$ in the hot-spot temperature for mineral oil and a decrease of $1 \%$ for both vegetal oils.

\begin{tabular}{|c|ccccc|}
\cline { 3 - 5 } \multicolumn{1}{c|}{} & \multicolumn{4}{c|}{ Table 4. Temperature obtained in each pass. } \\
\cline { 4 - 6 } \multicolumn{1}{c|}{} & $\mathrm{T}_{\mathrm{o}}\left({ }^{\circ} \mathrm{C}\right)$ & $\mathrm{T}_{\mathrm{w}}\left({ }^{\circ} \mathrm{C}\right)$ & $\mathrm{T}_{\mathrm{h}}\left({ }^{\circ} \mathrm{C}\right)$ & $\mathrm{HSL}$ \\
\hline Mineral oil & 78.6 & 84.8 & 106.4 & Disc 74 \\
\cline { 1 - 3 } $\begin{array}{c}\text { Vegetal oil } \\
1\end{array}$ & 77.7 & 83.1 & 104.6 & Disc 67 \\
\cline { 1 - 3 } $\begin{array}{c}\text { Vegetal oil } \\
2\end{array}$ & 74.8 & 81.9 & 102.5 & Disc 67 \\
\hline
\end{tabular}

\subsubsection{REST OF CASES}

The values of $\mathrm{T}_{\mathrm{h}}$ obtained in each case is shown in Figure 12. For mineral oil, a remarkable decrease is appreciated when the number of passes increases. A higher number of passes means less horizontal channels for the oil to cross from one axial duct to the other, increasing velocities in these channels. This effect provides a better heat exchange. For vegetal oils, their higher viscosity becomes more important with the increase of the oil path and velocity, compensating this previous effect.

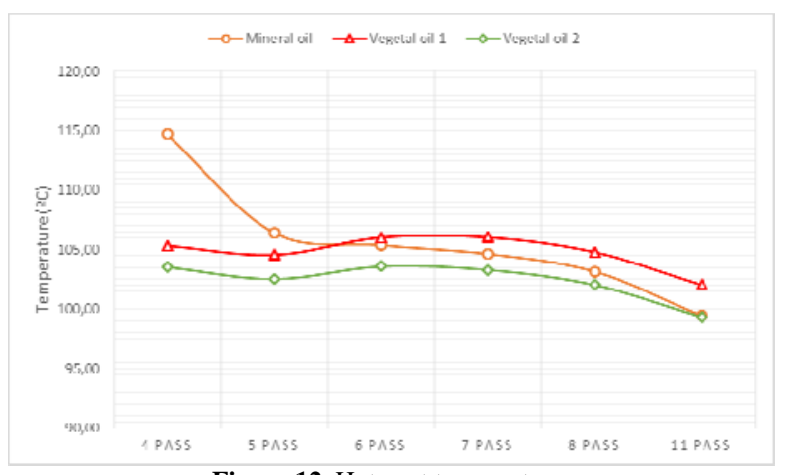

Figure 12. Hot spot temperature.

Moreover, it can be observed that with a higher number of passes, the value of $T_{h}$ of the three liquids is similar which means that for a high number of passes. This is caused by the fact that the hydraulic properties of the mineral oil (viscosity and density) balances its worse thermal properties with respect to vegetal oils.

Figure 13 shows the value of $\mathrm{H}$ obtained in all cases analyzed. It can be appreciated that for vegetal oils, the efficiency is higher with a low number of passes (higher number of discs per pass) whereas for the mineral oil the most efficient cases are the intermediate ones. The reason is that a higher number of passes produces a higher pressure drop, decreasing the efficiency although the hot-spot temperature is reduced.

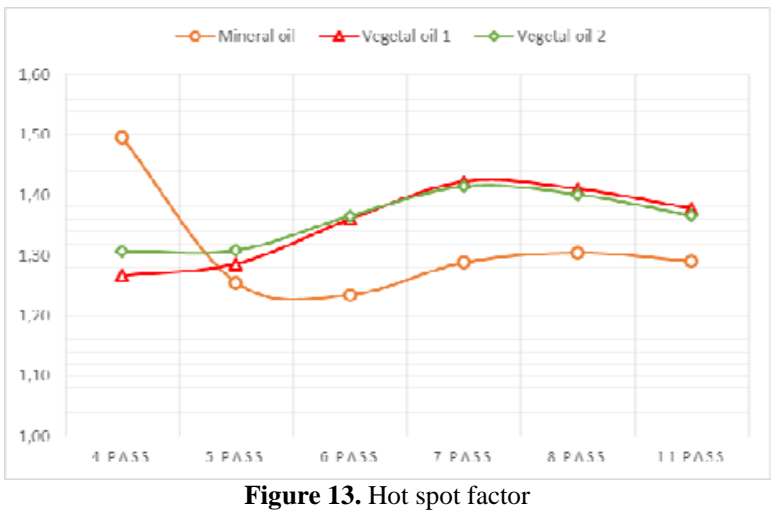

\subsection{PRESSURE DROP}

The cases presented above are considered to have equal mass flow rate and temperature at the inlet. Under these conditions, natural esters have a better thermal performance than mineral oils, that increases with an increasing number of passes. However, to reach the same inlet conditions, the pressure drop obtained with natural esters is higher than mineral oil. The same situation happens when increasing the number of passes.

Figure 14 shows the pressure drop, under isothermal conditions, of all cases considered in this study, where the value of $100 \%$ corresponds to the pressure drop of the reference case.

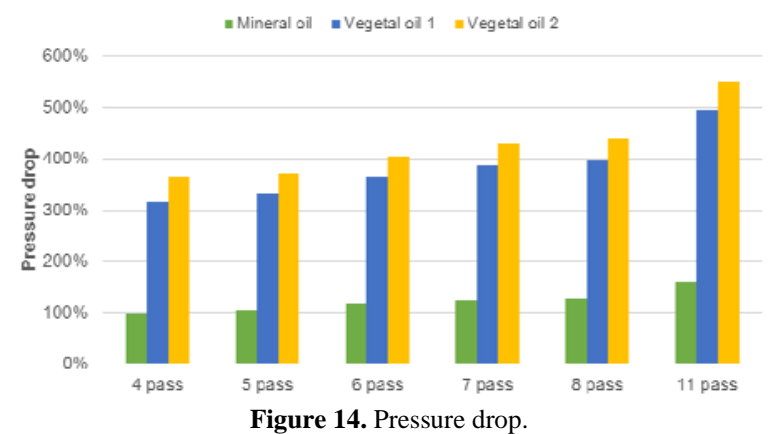

In Figure 14 can be observed that the pressure drop of natural esters is more than three times the pressure drop with mineral oil.

When considering non-isothermal conditions, the total winding pressure drop decreases due to buoyancy forces. Figure 15 shows the magnitude of the thermal driving force in the winding, under the same scale as Figure 14.

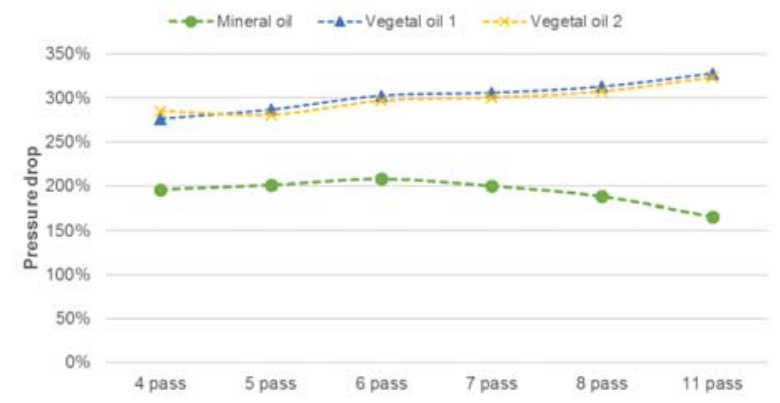


transformer winding," Appl. Therm. Eng., Vol. 30, No. 14-15, pp. 2034-2044, 2010.

\section{CONCLUSIONS}

Based on the results presented in the previous sections, some conclusions are obtained. For the base case, the use of vegetal oils as dielectric liquids produces a lower hot-spot temperature than the obtained with mineral oil, which means that both vegetal oils have better thermal properties when having the same mass flow inlet.

For mineral oil, when increasing the number of passes, a lower hot-spot temperature is obtained, thus improving the cooling efficiency with respect to the base case. On the other hand, for vegetal oils this temperature remains in a low range of temperature in all cases studied. Therefore, vegetal oils are more indicated for a lower number of passes whereas mineral oil behaves as good as vegetal oils when increasing the number of passes.

For all liquids studied, hot streaks appears in the oil, which causes higher temperatures than expected for the first discs of the pass where they appear. These hot streaks are caused by the detachment of the thermal boundary layer. For mineral oil also appears cold streaks, which are two hot streaks, an inner and an outer one, that are not coupled, resulting an oil stream at lower temperature.

Finally, the pressure drop obtained for natural esters is over three times the pressure drop obtained with mineral oil, which implies changing the pressure source necessary to reach the reference conditions. Taking into account the thermal driving force, natural esters produce more buoyancy than mineral oil, but they need to work under OF regime to reach the same inlet conditions. This means that the pumping cost increases for the esters due to the higher viscosity of these liquids.

\section{ACKNOWLEDGMENT}

The author of this work would like to acknowledge to the Spanish Ministry of Science for the financial support to the National Research Project: Performance of the insulating systems in transformers: alternative dielectrics, thermalfluid modelling and post-mortem analysis (DPI2013-43897P).

Also Mr. Santisteban would like to acknowledge to the University of Cantabria and the Government of Cantabria for the financial support for the Ph.D. scholarship (CVE2015-11149).

\section{REFERENCES}

1] I. Fernández, A. Ortiz, F. Delgado, C. Renedo, and S. Pérez, "Comparative evaluation of alternative fluids for power transformers," Electr. Power Syst. Res., Vol. 98, pp. 58-69, 2013.

[2] J. M. Mufuta and E. Van Den Bulck, "Modelling of the mixed convection in the windings of a disc-type power transformer," Appl. Therm. Eng., Vol. 20, no. 5, pp. 417-437, 2000.

[3] N. El Wakil, N.-C. Chereches, and J. Padet, "Numerical study of heat transfer and fluid flow in a power transformer," Int. J. Therm. Sci., Vol. 45, No. 6, pp. 615-626, 2006.

[4] F. Torriano, M. Chaaban, and P. Picher, "Numerical study of parameters affecting the temperature distribution in a disc-type
[5] J. Gastelurrutia, J. C. Ramos, G. S. Larraona, A. Rivas, J. Izagirre, and L. Del Río, "Numerical modelling of natural convection of oil inside distribution transformers," Appl. Therm. Eng., Vol. 31, No. 4, pp. 493-505, 2011.

[6] M. A. Tsili, E. I. Amoiralis, A. G. Kladas, and A. T. Souflaris, "Power transformer thermal analysis by using an advanced coupled 3D heat transfer and fluid flow FEM model,” Int'l. J. Therm. Sci., Vol. 53, pp. 188-201, 2012.

[7] A. Skillen, A. Revell, H. Iacovides, and W. Wu, "Numerical prediction of local hot-spot phenomena in transformer windings," Appl. Therm. Eng., Vol. 36, No. 1, pp. 96-105, 2012.

[8] F. Torriano, P. Picher, and M. Chaaban, "Numerical investigation of 3D flow and thermal effects in a disc-type transformer winding," Appl. Therm. Eng., Vol. 40, pp. 121-131, 2012.

[9] V. A. Yatsevsky, "Hydrodynamics and heat transfer in cooling channels of oil-filled power transformers with multicoil windings," Appl. Therm. Eng., Vol. 63, No. 1, pp. 347-353, 2014.

[10]E. Rahimpour, M. Barati, and M. Schäfer, "An investigation of parameters affecting the temperature rise in windings with zigzag cooling flow path,” Appl. Therm. Eng., Vol. 27, No. 11-12, pp. 19231930, 2007.

[11] J. Zhang, X. Li, and M. Vance, "Experiments and modeling of heat transfer in oil transformer winding with zigzag cooling ducts,” Appl. Therm. Eng., Vol. 28, No. 1, pp. 36-48, 2008.

[12] J. Zhang and X. Li, "Oil Cooling for Disk-Type Transformer Windings - Part II: Parametric Studies of Design Parameters," IEEE Trans. Power Deliv., Vol. 21, No. 3, pp. 1326-1332, 2006.

[13] R. Hosseini, M. Nourolahi, and G. B. Gharehpetian, "Determination of OD cooling system parameters based on thermal modeling of power transformer winding," Simul. Model. Pract. Theory, Bol. 16, No. 6, pp. 585-596, 2008

[14] M. A. Taghikhani and A. Gholami, "Prediction of hottest spot temperature in power transformer windings with non-directed and directed oil-forced cooling,” Int. J. Electr. Power Energy Syst., Vol. 31, No. 7-8, pp. 356-364, 2009.

[15] M. Sorgic and Z. Radakovic, "Oil-forced versus oil-directed cooling of power transformers,” IEEE Trans. Power Deliv., Vol. 25, No. 4, pp. 2590-2598, 2010.

[16] R. Girgis, M. Bernesjo and G.K: Frimpong, "Detailed performance of a 50 MVA transformer filled with a natural ester fluid versus mineral oil, CIGRE session Paris, A2-107, 2010

[17] T.-W. Park and S. H. Han, "Numerical analysis of local hot-spot temperatures in transformer windings by using alternative dielectric fluids,” Electr. Eng., Vol. 97, No. 4, pp. 261-268, 2015.

[18] R. Lecuna, F. Delgado, A. Ortiz, P. B. Castro, I. Fernandez, and C. J. Renedo, "Thermal-fluid characterization of alternative liquids of power transformers: A numerical approach,” IEEE Trans. Dielectr. Electr. Insul., Vol. 22, No. 5, pp. 2522-2529, 2015.

[19] S. Moore, K. Rapp and R. Baldyga, "Transformer insulation dry out as a result of retrofilling with natural ester fluid,” PES T\&D 2012, pp. 1 - 6, DOI: 10.1109/TDC.2012.6281441.

[20] IEEE Std C57.147 TM-2008. IEEE Guide for Acceptance and Maintenance of Natural Ester Fluids in Transformers.

[21] IEEEon section PC57.147TM/D3. Draft Guide for Acceptance and Maintenance of Natural Ester Fluids in Transformers.

[22] D. M. Mehta, P. Kundu, A. Chowdhury, V. K. Lakhiani and A. S. Jhala, "A review on critical evaluation of natural ester vis-a-vis mineral oil insulating liquid for use in transformers: Part 1." IEEE Trans. Dielectr. Electr. Insul., Vol. 23, No. 2. pp. 873- 880, 2016.

[23] D. M. Mehta, P. Kundu, A. Chowdhury, V. K. Lakhiani and A. S. Jhala, "A review on critical evaluation of natural ester vis-a-vis mineral oil insulating liquid for use in transformers: Part II.” IEEE Transactions on Dielectrics and Electrical Insulation. Year: 2016, Volume: 23, Issue: $3 . \quad$ Pages: 1705-1712, DOI: 10.1109/TDEI.2016.005371

[24] I. Fernández, F. Delgado, F. Ortiz, A. Ortiz, C.J. Renedo and A, Santisteban, "Thermal degradation assessment of Kraft paper in power transformers insulated with natural,” Appl. Therm. Eng., Vol. 104, pp. 129-138, 2016.

[25] IEC 60076-2, "Power transformers - Part 2: Temperature rise for liquid-immersed transformers.” 2011. 


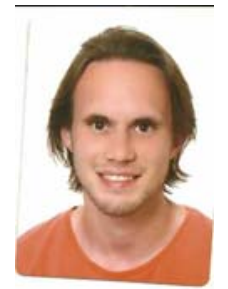

Agustín Santisteban was born in Colindres, on 28 June 1992. He received the M.Sc. degree in industrial engineering in 2015 and he is currently pursuing the Ph.D. degree from the University of Cantabria (UC), Spain. Finally, his main research topic is currently the study of the alternative dielectric liquids in power transformers.

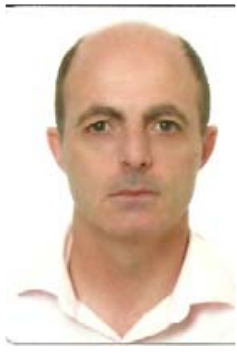

Fernando Delgado was born in Santander, on March 26, 1968. He received the M.Sc. degree in industrial engineering in 1998 and the Ph.D. degree in 2011 from the University of Cantabria (UC), Spain. Currently, he is Associate Professor in the Electrical and Energy Engineering Department of the UC. He has published over 25 works in international conferences and 13 papers in journals included in the Journal of Citation Report. Finally, his main research topic is currently the study of the alternative dielectric liquids in power transformers.

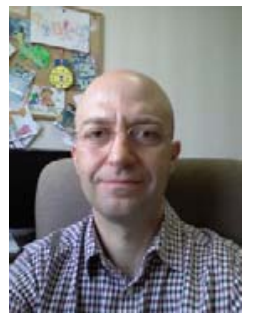

Alfredo Ortiz was born in Santander, on 9 September 1971. He received the M.Sc. degree in industrial engineering in 1997 and the Ph.D. degree in 2005 from the University of Cantabria (UC), Spain. Currently, he is Associate Professor and the Head of Electrical and Energy Engineering Department at the UC. He has published six chapters in international books, over 50 works in international conferences and XX papers in journals included in the Journal of Citation Report. Finally, his main research topic is currently the study of the alternative dielectric liquids in power transformers.

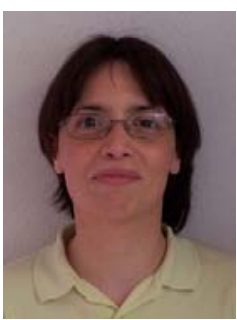

Inmaculada Fernández was born in Zaragoza, on 31 July 1981. She received the M.Sc. degree in chemical engineering in 2004 and the Ph.D. degree in 2009 from the University of Cantabria (UC), Spain. Currently, she is Assistant Professor in the Electrical and Energy Engineering Department of the UC. She has published two chapters in international books, over 20 works in national and international conferences and 9 papers in journals included in the Journal of the energy saving. Citation Report. Finally, her main research topic is

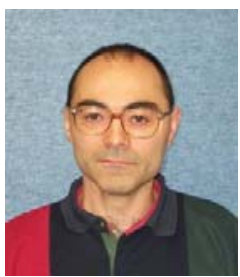

Carlos J. Renedo was born in Santander, on 3 November 1969. He received the M.Sc. degree in industrial engineering in 1997 and the Ph.D. degree in 2002 from the University of Cantabria (UC), Spain. Currently, he is Associate Professor in the Electrical and Energy Engineering Department of the UC. He has published over 50 works in international conferences and 24 papers in journals included in the Journal of Citation Report. Finally, his main research topic is the energy saving.

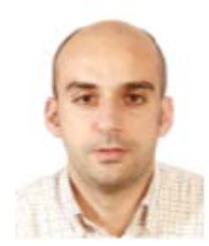

Félix Ortiz received the MSc degree in physical sciences in 2000 and the PhD degree in 2016 from the University of Cantabria (UC), Spain. $\mathrm{He}$ is Aggregate Professor of Electrical and Energy Engineering Department, UC. He has presented more than 10 papers at international conferences, and has published four journal papers. His main research topic is currently transformers. 